\title{
Seeing Relation: The Perceptual Event in Olafur Eliasson's Art
}

\author{
KATRINE ANNESDATTER-MADSEN
}

The installations of the Danish-Icelandic contemporary artist Olafur Eliasson are composed of a few different materials that create a simple visual appearance. In many works materials taken from nature, like fog, light, water, stone, wood, and ice play a leading role. Usually, they are arranged in a way that displays their materiality rather than used to represent something else. The artwork is its materiality - it is light, water, stone, wood, ice, and fog. Through my analysis of two artworks, this chapter explores the implications of Eliasson's technique in which the materiality becomes sensible: Beauty (1993), an installation of light and water in which a rainbow appears, and Riverbed (2014), an installation of a riverbed made of stones and water. I argue that, above all, Eliasson encourages the viewer to perceive the materiality - the colors of the rainbow and the stoneswhereby it can be discovered that perception is relational.

Gilles Deleuze's writings on art show great interest in art with a particular focus on letting the materiality be sensed. He coined the term "signaletic materiality" to describe the emphasis on materiality rather than representation that characterizes the emergence of a new type of expressionist cinematic aesthetic after WW2. Deleuze highlights in particular Carl Th. Dreyer, Andrej Tarkovskij, and Jean-Luc Goddard for their exploration of ways to make the filmic materiality sensible: ruptures in the diegesis, the insertion of dark and white spaces, the decoupling of sound and 
image track, or the use of certain colors to name only a few techniques. As such, these directors challenged a classical understanding of the film as a linquistic sign. The signaletic material:

includes all kinds of modulation features, sensory (visual and sound), kinetic, intensive, affective, rhythmic, tonal [...] this is neither a language system nor a language. It is a plastic mass, an asignifying and a-syntaxic material, a material not formed linguistically (Deleuze 2013, 29).

Deleuze's work on signaletic materiality was published in Cinema 2: The Time-Image in 1985. However, the term elaborates on analytical points made in his 1981 book Francis Bacon: The Logic of Sensation (2003). Here, Deleuze praises the painter's use of color because it breaks with figuration/representation. It does so by enabling a perception of the fact that the colors are relational, that is, virtual appearances actualized in perception. The problem with visual modes of representation is the precedence of form and figure over materiality. Suppressing materiality in favor of figuration does not let the virtual plane be felt (Deleuze 2003, 125-127). Instead, the world of the figuration appears as separate from the world of the perceiver instead of simultaneously appearing with and in perception. In this way, visual representation comes to be aligned with Cartesian visual perception, a perceptual mode that is characterized by the idea that vision produces disembodied and objective registrations of a predefined world (Jay 1988).

Rather than composing visual representations, Beauty and Riverbed accentuate their materiality. The viewer can thereby discover that visual experience is a continuous folding of perception and materiality. This folding of perception and materiality is key to understanding the dynamic of the interface as theorized by Anna Munster (2006). Clearly, Beauty and Riverbed are not digital interfaces. However, by exploring the effects and possibilities of relationality, I argue that Beauty and Riverbed stretch the boundaries for how we can think interface-events.

Although I will not use the term 'interface,' my analysis explores the same relational exchange between bodies that Munster stresses in her definition. Munster's point of departure is the Spinozian understanding of the body. Whatever the nature of a body, it can differentiate itself in 
relation to other bodies, because bodies have the capacity to affect and be affected. This idea of the body as open and changeable enables Munster's rethinking of the interface and is at the base of her definition:

Affect arises relationally and is produced out of the difference between being in the body and representing/mapping the body from the outside. Affect sustains the singularity of sensing and of representing as a differential experience of embodiment, one in which alterity has a place (Munster 2006, 142).

My analysis of Beauty and Riverbed describes how the perception of materiality can give rise to perceptions of differential experiences of embodiment. Perceiving such bodily movement enables explorations of the body as a perceiving agent that takes part in a "worlding" (Brunner 2012). Brian Massumi asserts that bodies can differentiate because the capacity to affect and be affected governs a transition in which "a body passes from one state of capacitation to a diminished or augmented state of capacitation" (Massumi 2009, 1). Furthermore, Massumi stresses that this transition has to be felt (ibid.). In Beauty and Riverbed, this capacitation of the body becomes perceivable as a potential that shapes visual experience.

Massumi's concept of "thinking-feeling" elaborates on Deleuze's work on visual art and signaletic materiality. Thinking-feeling is about the creativity of perception as it describes how perception continually 'doubles' or enfolds the world by adding potential to it. This potential becomes manifest in vision. What we actually see is always doubled with its own (virtual) potential. Therefore, vision has both actual and virtual dimensions. Vision is not an objective registration of what is actually in front of our eyes; rather, it is an abstraction. We literally see potential by seeing imperceptible qualities that are not 'there' in an actual sense. What we see is a "life dynamic" because we see the body live a virtual relation (Massumi 2011, 42). For instance, when we see an orange, what we actually see is a two-dimensional round shape with different shades of orange. Color is what we actually see, because color is what the visual sense produces. Though we see the two-dimensionality and color of the orange, what we perceive is three-dimensionality, and we can't choose to stop 'seeing' that volume.

This means that we see more than what is actually visible. There is more to vision than the color the visual sense produces. This is because other senses participate virtually, thereby making vision synesthetic. Volume is a quality that appears virtually because it pertains to kinesthesia 
(sense of movement). Volume can only appear in visual perception because perception creatively think-feels the shape of the orange and so a relay of vision into kinesthesia takes place. Perception feels the qualities of the orange and thinks the potential it holds in respect to the body's ability to relate (Massumi 2011, 50). We are "seeing, in a real way, [...] our capacity to see the other side [...], the potential our body holds to walk around, take another look, extend a hand and touch" (Massumi 2011, 42). Another thing we see is weightiness, which we see through texture. Weightiness pertains to propriocention and texture to the sense of touch. In an actual way, the granulated surface of the orange can be seen as nuances of orange and different relations of shadow and light. The composition of color, light, and darkness activates a virtual sense of touch as perception imagines how the texture would feel, but also how it would feel to lift and hold in our hand.

There is therefore a relay of vision into both the sense of touch and proprioception. What constitutes our ability to see the orange in its three-dimensionality is this actualization of virtual qualities in visual perception. But typically we don't notice this relational shaping of visual experience, instead we just grab the orange and let the qualitative dimension of the lived experience pass. It means that we don't feel the capacitation because we live out the affordance of the thing, that is, its potential for interaction, rather than we notice the emergence of that potential in perception. Massumi's point is that as long as the potential the thing holds for interaction remains a potential, that is, as long as we don't actually move towards the orange and take it in our hand, the stronger the qualities of the lived virtual relation will appear in visual perception.

As a result, there is a difference between interaction and relation. While interaction refers to the instrumentalization of objects through reducing them to their primary functions, relation refers to the experience of the full spectrum of virtual qualities accompanying every perception of an object. Experiencing the virtual dimension of an object makes it a "semblance" (Massumi 2011, 15). When interacting with an object, the semblance is backgrounded in favor of its instrumental function:

Interaction is just that: a going back and forth between actions, largely reduced to instrumental function. The lesson of semblance is that lived reality of what is happening is so much more, qualitatively. It includes an 'uncanny' moreness to life as an unfolding lived relation in a world whose every moment is intensely diffused with virtuality — an abstractly felt 'backside', or voluminousness, or life itself (Massumi 2011, 46, italics original). 
With this distinction in mind, the problem of visual modes of representation is that they align with the interactive mode of perception: they display already 'finished' and formed objects and the interaction circuits between them. This means that the virtual dimension of the object is unperceived. The following analysis will explore how Beauty and Riverbed highlight their materiality and thereby make the lived virtual relation perceivable.

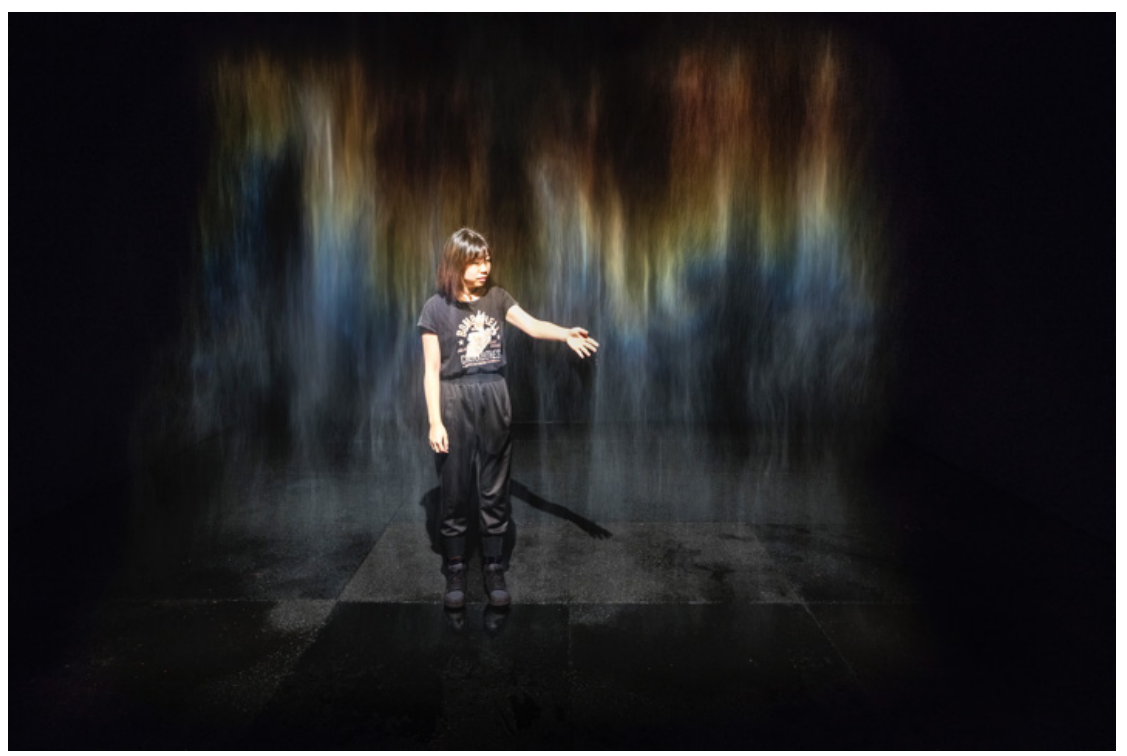

Figure 1. Beauty, Olafur Eliasson, 1993. Installation view at Long Museum, Shanghai, 2016. Photo credits: Anders Sune Berg.

\section{BEAUTY}

Beauty has become an icon of Eliasson's practice. Since its creation in 1993, it is one of his most exhibited artworks and was also part of his large 2019 retrospective In real life at Tate Modern. The installation features a spotlight hanging in the middle of a dark room pointing at a formation of vaporized water droplets falling from the ceiling. When entering the space from the side, the formation appears whiteish (the formation is not just white but ranges from dark to white with all kinds of greyish and whiteish 
nuances in between). The fog vibrates as it falls from the ceiling, so the light continuously hits it differently; even if the spectator stands still, the appearances vary. Moving closer to the center of the floor, slight changes in the whiteish appearances emerge; moving closer still, colors begin to pop out on the crest of the waves of the fog. The colors intensify with every step, until eventually a rainbow-like spectrum of predominantly red, yellow, orange, purple, and blue colors appears. Red and blue light radiate most vibrantly, while the whiteish reflection has almost disappeared. Upon continuing toward the side of the blanket of fog, the colors fade until there is only darkness. When moving in the opposite direction towards the entrance of the space, the colors appear once again, as eventually does the whiteish formation. If moving back towards the center (whether closer to the fog or farther away from the fog), the rainbow doesn't appear, only the whiteish reflection. In the following, I will dwell on how these appearances can be understood in relation to the difference between interaction and relation discussed above.

\section{THE CODED SPACE OF THE WHITEISH APPEARANCE: INDIFFERENT BODIES}

The appearance of the whiteish light is less sensitive to movement than that of the rainbow. By that I mean that gallery guests can walk around in large areas of the 'white zone' and only experience slight changes between light and darkness. This alteration is solely caused by a change in the contrast between the number of droplets reflecting the light and those not. Accordingly, the whiteish appearance is part of a spectrum ranging from darkness to whiteish light. Darkness or dark spots are the results of absence of light. The dark spots are located in the fog either where there are no droplets or where the droplets being hit by the light are not reflecting the light in the direction of the spectator's eyes.

When the fog goes from being illuminated to being dark, it is only possible to see the spotlight itself and the darkness (which you don't really 'see'). The rays of the spotlight become absorbed by the darkness of the room. Therefore, the spotlight hanging in the darkness can be likened to a mathematical point. As such, it can be comprehended like a code of a binary shift between on and off: light and no light. 
This optic code is almost infinitely reproduced by the spatialization introduced by the fog. The code is spatialized when the reflections of the light by the droplets become within reach of the eyes of the spectator when moving into the white zone. The reflecting fog reproduces the optic code because its mirroring does not cause a visible qualitative change in the constitution of the light. The light quality of the spotlight appears to be merely transferred to the droplets. This means that the mathematical point of the spotlight is multiplied by the mirroring of each droplet. The droplets scatter the light widely in the room and towards the spectator. This scattering makes the whiteish appearances less sensitive towards her movement. Accordingly, this makes the whiteish appearances visible from many locations on the floor.

In Francis Bacon: The Logic of Sensation (Deleuze 2003), Deleuze attributes an optically coded space to Abstract Expressionism. Because this space can be counted as binary digits, it can also easily become a mere symbolic coding of the figurative (Deleuze 2003, 109). The modulation of light and darkness appeals to a purely optical function or distant vision. This means that what is seen appears to be separated from as well as preexisting the viewer. In Beauty, the fog does not represent a figuration, but delineates a spatial extension. Therefore, the whiteish appearance has an affinity with the naturalistic painting style. This style creates space and volume by means of different relations between light and darkness (among other techniques) to trigger a linear perception of space (Deleuze 2003). The light illuminating the extension of the fog effectively outlines its three-dimensionality. As a result, the light doesn't add a spatial quality to the fog; rather, it illuminates and reveals the space already created/ delineated by the fog. As such, the fog preexists its own illumination by the light. Therefore, perception is interpellated into a certain spatial order. In this mode of perception, the feeling of movement in the body when the vision of volume is brought out by perception is obstructed. Deleuze states (paraphrasing Francis Bacon) that optical space lacks sensation since it "unlocks areas of sensation" (Deleuze 2003, 102). By this, Deleuze means that the optical space has no capacity to make the affective impingements felt, because it doesn't exert "direct action upon the nervous system" (Deleuze 2003,109). Instead, it merely "internaliz[es] tension in the optical form," which causes its neutralization (Deleuze 2003,109). So, the whiteish light makes it difficult to perceive the relational activation of perception, 
that is, the actualization of volume in visual perception. Therefore, the whiteish fog will appear as a mere gathering of individuated entities: the fog, the light, and the body of the viewer. Accordingly, the encounter between perception, light, and fog can be said to be characterized by indifference. That is because when seeing the spatial representation, the virtual quality of volume that constitues visual perception of that space is hard to feel. Neither does the encounter between fog and light cause a qualitative change in the constitution of the light. Therefore, we can say that the responsiveness of the whiteish appearance is merely interactive rather than relational or interfacial. In order for the encounter between the spectator and the whiteish fog to be characterized as an interface, there has to be a relational exchange in which the capacitation of the body resulting from the encounter becomes perceivable. Since the encounter between the spectator and the whiteish fog neither leads to a qualitative change in the constitution of the light (it remains whiteish) nor does the quality of volume become perceived as bodily movement and differentiation, it can be characterized as an interactive exchange. It means that the interaction between the body of the fog and spectator can go on in endless circuits, but they will not lead to qualitative change in the nature of either.

\section{THE THINKING-FEELING OF VISION: SEEING POTENTIAL IN THE REFRACTED LIGHT}

As explained above, optic space could be seen as distant from the spectator due to the spatial representation of light and darkness. However, a qualification by way of modulating colors exercises an intimate closeness upon vision. The colors replace the optical space with the sensation of color. Deleuze writes:

The modulation of color, on the contrary [compared to the modulation of light and darkness], recreates a properly haptic function, in which the juxtaposition of pure tones arranged gradually on the flat surface forms a progression and a regression that culminates in a close vision (Deleuze 2003, 133).

Deleuze elaborates on the concept of the haptic from the art historian Alois Riegl (Riegl 1985; see also Thomsen 2018). In his reading of Riegl, haptic vision describes the perception of a surface (for instance, a canvas or reliefs) in which virtual qualities such as texture become visually perceivable because it can be seen how the canvas feels to touch. Haptic 
vision enables a perception of perception's thinking-feeling because the hand's potential interaction with the surface becomes manifest as a visual feeling of touch. The modulation of color that Deleuze attributes to Bacon describes a vision of the spatial qualities of color, a virtual movement. When the colors modulate, they 'detach' from the surface on which they are painted and move. Deleuze refers the virtual movement of color to haptic visuality. That is because the modulating colors make perceivable that the movement happens in visual perception, in the optic nerve so to speak. As such, they enable a perception of the fact that the colors are virtual actualizations; in other words, they actualize in visual perception in relation to the materiality of a canvas (e.g. paint). Therefore, the colors do not preexist the viewer and the viewing situation, but appear in relation to both.

The ephemeral colors of Beauty are not subordinated to a certain shape or figure, but are visual abstractions. This makes their spatial qualities perceivable. Therefore, the rainbow appears as a modulating space of colors. The spatialization of each color creates a felt perception of movement and volume. The two most radiant colors are red and blue. They delimit the rainbow from the darkness at the top of the artwork and the more whiteish fog at the bottom. Even though the fog vibrates and moves, the contrast between red and blue creates tension in the eye as they detach from the materiality of the fog and free-float. As such, the movement of the colors is different from the vibrations of the fog. The red color progresses or advances while the blue regresses or contracts. Vision is turned in on itself as the contrast between seeing colors move from 'outside' the body and feeling their closeness as movement and volume from 'inside' the body is diminished and becomes indiscernible. The dynamism of vision itself, its relational becoming from moment to moment, can be perceived as a thinking-feeling of vision while happening. Thinking-feeling the qualities of the colors makes clear that the colors do not preexist but are brought out by perception in relation to the refracted light.

Where indifference characterized the encounter between the light, fog, and perception in the whiteish appearance, the dynamic appearances of color express the relational event happening between all three. The relation appears within an angle of 40-42 degrees formed by the spectator and the rays of the light in relation to the fog. Here, the rays pass through the front of the droplets, causing their refraction. Subsequently, the rays hit 
the back of the droplets where they are refracted once again and mirrored. The mirroring of the refracted rays directs the rays towards the spectator to be caught by her eyes. The rays are thus seen as a color spectrum or rainbow. The whiteish appearance is therefore not to be considered as contrary to the rainbow but as its constituent. The rainbow expresses the differentiation of the light by the fog and the differentiation of the body by the refracted light. Therefore, the rainbow can be described as, in Massumi's words, a virtual "pop-out dimension" of the whiteish appearance. Massumi explains the relation between the virtual and actual as follows:

The virtual is the pop-out dimension of the actual whereby it really, appearingly, exceeds itself. The virtual is the excessive dimension of the in-act as it throws itself into experience over and above its sensuous conditions. It is the dodgy, supervenient manner in which the actual effectively appears to include more than can be sensuously counted for: a reality of the abstract. The appearance of an abstract locus nonsensuously filled with a spectral being of relation (Massumi 2014, 60, italics original).

The virtual is more than can be sensuously counted for. In this context, 'sensuous' refers to the parts of Beauty that are actually there: the fog, the light, and the perception of the spectator. What sensuously hits the eyes of the spectator is the light after it's refracted by the fog, but the rainbow seen by the spectator can neither be reduced to the refracted light nor to perception alone. The rainbow appears relationally and is therefore more than both. The rainbow is a 'nonsensuous' reality because it has reference only to an abstract, virtual plane. The colors are abstract and virtual, because we don't see the light electrons hitting the retina and affecting the optic nerve. Vision is an expression of how the body deals with the activity in the body caused by the electrons. The body takes their activity into its own by transforming it into an event of color (Massumi 2011, 27). The modulation of color, the thinking-feeling of vision itself, is as such an expression of the body's own capacity for relation as activated by the impinging refracted light electrons. It is a perception of the body in the midst of processing their activity.

Moving on to an analysis of Riverbed, I will explore the ways in which the installation invites a thinking-feeling of a landscape full of ordinary stones to be perceived anew as an event. Hereby, the installation stresses the virtual as a memory that constitutes the felt potential. That is because it becomes impossible to see the same stone the same way twice. 


\section{RIVERBED}

Riverbed was installed for the first time in 2014-2015 in the south wing of the Louisiana Museum of Modern Art in Humlebæk, Denmark. In 2019, the installation opened at Queensland Art Gallery in South Brisbane during Australia's devastating summer drought and bushfires. As one reviewer pointed out, in this context the freshness and humidity of Riverbed came to act as a kind of parallel world of possibility in which a different future could be experienced and imagined. ${ }^{1}$

Riverbed covers the wooden flooring of the exhibition space with stones and gravel in various shades of blue and gray. A small brook runs in the middle. The floor has been elevated so that the landscape slopes gently upwards. The walls are left white, and as far as the eye reaches from the entrance, the same kind of landscape continues in the following rooms.

The space does not hierarchize elements: paintings and objects placed on the floor are not given a higher status than the space in between. Brian O'Doherty (1986) argues that the point of each gallery space is to transmit value to the objects placed in it. This also applies to Riverbed. But usually, this transmission of value entails that movement and the distance to be covered between the artworks is subordinated to the separation of the objects of display. The visuality of Riverbed clashes with such organization of space and movement. Its organization of space can be compared to the haptic, ornamented style of pre-classical Egyptian reliefs as analyzed by Riegl (Riegl 1985; Deleuze 2003). The Egyptian reliefs are flat, and their ornamentation is characterized by sparse figuration. Their visual patterns are repetitious and they expand endlessly and continuously across the surface. The emphasis on the two-dimensional plane rather than a three-dimensional space makes the visuality of the ornamentation haptic. That is because it invites a close-up perception of its material qualities which brings to the fore a perception of how perception thinkfeels the materiality. The haptic, close perspective enables the viewer to see how the materiality feels, as if the eyes could act like hands and touch the ornaments.

Riverbed fills out the space in a continuous manner similar to that of Egyptian ornamentation. The non-hierarchical organization of the space doesn't offer any visual breaks or interruptions: no spectacular object stands out from Riverbed's gray-blue ornamentions. Rather, because the ornamentation directs attention only to the stones and gravel inside 

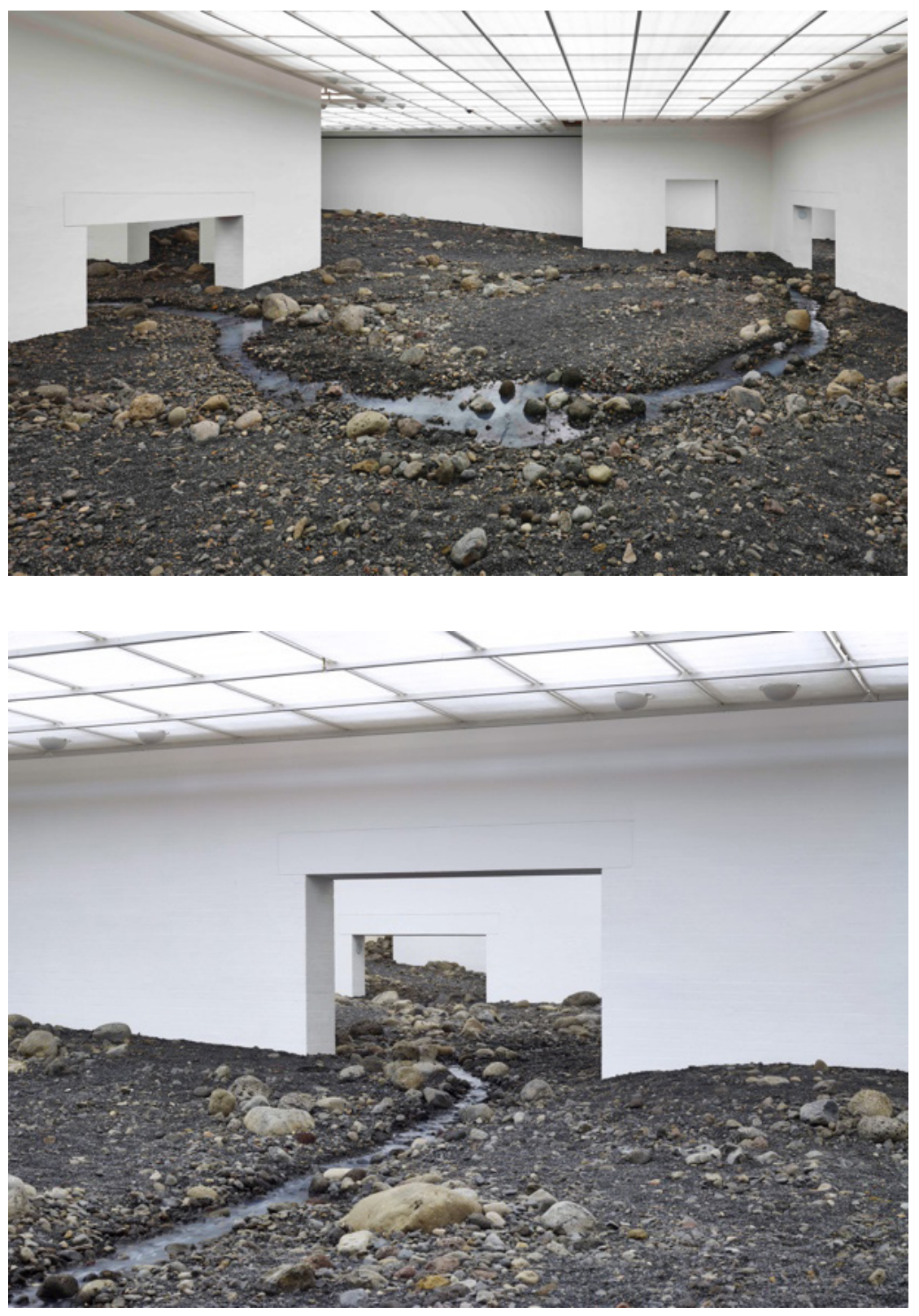

Figures 2 \& 3. Riverbed, Olafur Eliasson, 2014. Installation view at Louisiana Museum of Modern Art. Photo credits: Anders Sune Berg. 
this place, it disrupts any instrumentalization of movement itself. The stones do not function as an obstacle that needs to be covered in order to go somewhere or see something other than what can be seen in the space. Rather, the stones themselves, as well as the act of walking them, is the attraction of the installation. Riverbed's space of seeming nothingness is not entertaining; it doesn't impose a behavior or attitude upon the viewer. Rather, its statement is quite clear: if one decides to stay in this space, one can experience what happens when nothing happens.

\section{WALKING THE IMPERCEPTIBLE}

Riverbed is hard to walk. The stones and gravel make it difficult to maintain a sense of direction. In order to avoid stumbling over the stones, slipping on the gravel, or getting wet shoes, the walker has to look down and pay attention to the ground in her most immediate surroundings.

This haptic ornamentation is everywhere in Riverbed. The installation consists of its relationalities and these compose its value. It invites walking in a haptic manner which is a bit like orienteering in a desert, or, as a matter of fact, walking an Icelandic riverbed: a walk in which there are no, or only minimal, visual coordinates according to which the walker's movements could be measured. Thus, the visual mode of functioning changes when walking through Riverbed. Outside the installation, navigation through the museum building and corridors was supported by the optical vision, a way of seeing predicated on distance (Deleuze \& Guattari 2014, 551f.). But inside Riverbed, the close, haptic vision must take over.

There is good reason for this change. The shape of each stone is unique, and the composition of these uniquely shaped stones makes up an uneven ground. The uneven ground means that the body has to adjust itself a little before each new step forward. No movement is the same. The challenging ground imposes an awakening and awareness upon the walker that can make her notice this adjustment of the body in the instant just before putting a foot on the ground and giving in to the weight of the body. This moment of preparation defines an anticipation of the future that is full of virtuality: the constitution of the ground just before the body is taken into account by means of the close-up perspective of the eyes. The volume, hardness, and tactility of each stone can be seen and experienced in the body. Without experiencing these potential qualities of the ground 
in the immediate surroundings, the walker would simply fall when stepping forward, it would feel like walking blindfolded. But because the body relates itself virtually to the stones, it doesn't fall. The thinking-feeling of each stone's degree of slipperiness, density, sharpness, or roughness prepares the body so that it knows how to move. This knowledge is based on the actualization of these virtual qualities in perception. We don't really know how the ground feels before we have put our feet on it. Nonetheless, we don't fall. We rely on these qualities because we have a history of interacting with stones. This history is what enables the qualities (of the past) to actualize in perception as a projection of the future

\section{QUALITATIVE DIFFERENTIALS}

To see the event of each stone is to see "through" to its qualities (Massumi 2011, 42). Seeing qualitatively means that the object is doubled by its own potential. When seeing each stone, what is actually seen is a pattern that describes only its visual appearance-its compositions of light, shadows, and gray-blue colors. This composition outlines a shape. The virtual doubling of the stone appears through this shape-pattern.

The difference between Riverbed and Beauty is that the latter is a purely visual, ephemeral and shapeless phenomenon. By contrast, the stones in Riverbed are not ephemeral objects because they consist of multiple qualities that pertain not only to the visual sense. By thinking-feeling the shape-pattern of the stones, the body's history of interacting with such shape-patterns is activated. The nonfiguration and shapelessness of Beauty suspends any interactive potential. That is why Beauty becomes an invitation for a thinking-feeling of vision itself, in which the typically unperceived relational dynamics of vision become perceivable. Since we normally perceive colors when they are governed by a shape, we tend to the interactive potential of the shape rather than the quality of the color itself, leading the color relationality to pass unnoticed. That is what happens in Riverbed: The objectness of the stones makes the thinking-feeling of the qualities pertaining to all the other senses except the visual perceivable: the sense of touch, kinesthesia, and proprioception. These qualities appear as an excess of the shape-pattern of each stone. Accordingly, seeing the stones qualitatively implies a vision less dominated by the colors and more of the potentials pertaining to the aforementioned non-visual senses actualizing in visual experience. 
As such, thinking-feeling the stones in Riverbed highlights the diagrammatic functioning of perception. Diagramming stresses the virtual relation lived to an object while the visual shape-pattern almost dissolves by the doubling of the objects' qualitative nature that passes through it. Diagrammatic perception is a perception of the abstract potential in the actual. ${ }^{2}$ It "is not concerned with reducing the world to an aggregate of objects" (Massumi 2011, 14). Rather, it is about attending to the genesis of the object-as a lived relation (ibid.). ${ }^{3}$

Therefore, the installation can be said to make perceivable the genesis of the stones and consequently of a landscape; the stones appear through the shape-patterns by the relay of the visual sense into the senses that can only appear virtually. In this way, seeing the virtual qualities may give rise to an awareness of the fact that the body has a history of interacting with stones like the ones in Riverbed. As such, the diagrammatic perception highlights the virtual as a memory integral to perception. That is because there can be no felt future potential (the anticipation mentioned before seeing how it would feel to place the foot on the stone ahead of the body) without a memory of how, in the past, it felt to interact with stones of shape-patterns like the ones in Riverbed. The felt potential and experienced qualities of actual perception are tied to the virtual as a memory that includes past experiences. Erin Manning explains the relation of shape-patterns to past and future potentials:

We see not only what we actually look at but what we remember ourselves seeing. What we remember ourselves seeing is actualized through non-sensuous perception, which refers to how an experience of pastness-past seeings-finds its way into our present as a force of potential. It's not just that we see what we've already seen-it's that what we've already seen contaminates what we feel we see and re-composes what we're actually not seeing (Manning 2009, 85).4

The virtual memory is what constitutes the body's capacity to project itself into the future by thinking-feeling the potential relations that could be lived to the shape-patterns. As such, the potential seen in the shape-patterns is not a memory of the past but of the future (Massumi 2009). In Riverbed, the body lives future relations to the stones by thinking-feeling their shape-patterns before the interaction (walking) is lived out. In this way, the time of walking the ground is a kind of past, because the walking has already happened virtually. The memory of past interactions with stones is thought-felt differently according to the specific shape and patterns 
posed by each stone. It means that the potentials experienced before walking over each stone in Riverbed will be different. The shape-pattern of each stone varies slightly as no two stones are completely identical. The way one stone appears with a larger amount of small dark spots because the surface is perforated can be seen as lighter than a stone whose surface is smoother and thus outlining a round shape. The two shape-patterns give rise to two different tactile experiences that relay into different experiences of weight and hardness. Each stone can be visually perceived as a qualitative differential because of the variation posed by each shape-pattern. 'Qualitative differential' refers to the slight variation posed by each stone compared to the 'stone-genre'. It means that what makes stones differ from each other is their different compositions of qualities (Massumi 2011, 49-50).

As the potential is felt in perception, the feeling will spur change in the constitution of the memory. Accordingly, each stone perceived qualitatively will change the constitution of the virtual. These particular felt qualities are 'added' to the memory pool, wherein they recompose the body. This implies that the kinds of potentials that can be felt in future perceptions of stones will be changed slightly. As such, the memory of (in this case) a stone as a generic shape-pattern is not stable but dynamic. Even though two identical stones may exist in Riverbed, the body will already have been moved after seeing and feeling the qualities of the first. They cannot be perceived as the same but two qualitative differentials.

As such, Riverbed is an invitation to discover the implications of diagrammatic perception for experiencing the world. Diagrammatic perception opens to experiences of difference and relation. What may at first look like an ordinary and familiar landscape in shades of gray could turn out to be nothing less than a novelty.

\section{CLOSING REMARKS}

Even though Beauty and Riverbed aren't digital interfaces, they explore the relationality of perception as underscored in Anna Munster's theory of the interface. The strong emphasis of the installations on letting the viewer perceive their materialites in a haptic way to foster a diagrammatic perception can be likened to the way a digital interface functions. As such, the artworks challenge understandings of the interface as a term that only comprises digital art and expand the current understanding of interface events. Eliasson's focus on creating haptic compositions rather than visual 
representations invite the viewer to perceive qualitatively. These moments of qualitative perception create differential experiences of embodiment which stress the fact that the body is a processual becoming with the capacity to affect and be affected. Thus, the way the appearances of Beauty and Riverbed unfold in perception is not predefined. The relational unfolding is conditioned by the particular compositions of the viewer's body and the materiality of the artwork. In both installations, the virtual actualizes in visual perception diagrammatically.

In Beauty, the colors are brought out by perception as virtual abstractions. The modulating colors express the perceptual act: perception in the midst of transforming/enfolding the impingement of the refracted light electrons. At the same time, the colors expose the relational event happening as 'popping out' of the whiteish appearance when the right conditions form between its parts: light, fog, and the viewer's perception. Therefore, the whiteish appearance is in itself merely interactive as it expresses an assemblage in which its parts are mostly indifferent to each other.

In Riverbed, the actualization in visual perception of qualities pertaining to the sense of touch, kinaesthesia, and proprioception makes it possible to navigate safely through the landscape. Before walking on the stones, these qualities appear virtually through the stone-patterns. The haptic organization of the space suspends an instrumentalized approach to movement. Instead it invites the walker to notice this diagrammatic perception in which the stones can be perceived singularly as different compositions of qualities because of the variations in each shape-pattern. Each shape-pattern activates the virtual as a memory of a generic form. But this generic form is also dynamic and continuously affected by the virtual qualities actualizing in perception. Perceiving Riverbed diagrammatically means that it would be impossible to perceive two stones the same way, even if they carried identitical shape-patterns. This makes Riverbed an invitation to discover the effects of diagrammatic perception for experiencing the world. In Riverbed, the ordinary landscape could be experienced anew-as an event.

\section{NOTES}

1. E.g. https://www.abc.net.au/news/2019-12-30/water-exhibition-brisbane-olafur-eliasson-angela-tiatia/11823782 [Accessed 22 June 2020].

2. 'Abstraction,' as it is used by Massumi, should not be the confused with the way I use the phrase 'visual abstraction.' See above, where I describe how seeing the colors in Beauty is an abstraction, because we can't see the electrons themselves. 
3. My interest in the diagram is inspired by Bodil Marie Stavning Thomsen's work on filmmaker Lars von Trier (Thomsen 2018). See also her elaboration on the concept in her chapter in this anthology (Thomsen 2021).

4. It should be noted that in this quote, Manning relates more to Bergson than to Deleuze in terms of referring specifically to 'past' and 'present' whereas Deleuze uses 'the virtual' to cover both past and future and 'actual' as the moment of actualization of the virtual.

\section{REFERENCES}

Brunner, C. (2012). Immediation as Process and Practice of Signaletic Mattering. Journal of Aesthetics and Culture [online] 4 (1). Available at: https://www.tandfonline.com/doi/full/10.3402/jac.v4io.18154 [Accessed 22 June 2020].

Deleuze, G. ([1970] 1988). Spinoza: Practical Philosophy. Translated by R. Hurley. San Francisco: City Lights.

Deleuze, G. ([1981] 2003). Francis Bacon: The Logic of Sensation. Translated by D. Smith. London \& New York: Continuum.

Deleuze, G. ([1985] 2013). Cinema 2. The Time-Image. Translated by H. Tomlinson \& R. Galeta. London: Bloomsbury.

Deleuze, G. \& Guattari, F. ([1981] 2014). A Thousand Plateaus: Capitalism and Schizophrenia. Translated by B. Massumi. London: Bloomsbury.

Jay, M. (1988). Scopic Regimes of Modernity. In: H. Foster, ed., Vision and Visuality. Seattle: Bay Press, pp. 3-28.

Manning, E. (2009). Relationscapes: Movement, Art, Philosophy. Cambridge: MIT Press.

Massumi, B. (2002). Parables for the Virtual: Movement, Affect, Sensation. Durham: Duke University Press.

Massumi, B. ([2008] 2009). Of Microperception and Micropolitics. Interview with Joel McKim. Inflexions [online] 3. Available at: http://www. inflexions.org/n3_massumihtml.html [Accessed 22 June 2020].

Massumi, B. (2011). Semblance and Event: Activist Philosophy and the Occurrent Arts. Cambridge: MIT Press.

Massumi, B. (2014). Envisioning the Virtual. In: M. Grimshaw, ed. The Oxford Handbook of Virtuality. New York: Oxford University Press, pp. 55-70.

Munster, A. (2006). Materializing New Media: Embodiment in Information Aesthetics. Hanover \& London: University Press of New England. 
O'Doherty, B. (1986) Inside the White Cube: The Ideology of the Gallery Space. Santa Monica \& San Francisco: The Lapis Press.

Riegl, A. ([1902] 1985). Late Roman Art Industry. Translated by R. Winkes. Rome: Giorgio Bretschneider Editore.

Thomsen, B.M.S. (2021) Interfacial Modulations of Affect: On the Creation of Events in Contemporary Art Works. In: B.M.S. Thomsen, J. Kofoed \& J. Fritsch, eds., Affects, Interfaces, Events. Lancaster \& Vancouver: Imbricate! Press, n.p.

Thomsen, B.M.S. (2018). Lars von Trier's Renewal of Film 1984-2014: Signal, Pixel, Diagram. Aarhus: Aarhus University Press. 